\title{
Development of Space Activity or the Republic of Kazakhstan: History and Modern (Political and Legal Aspect)
}

\author{
Svetlana Mikhaelovna Sylkina \\ Mariyam Sultanovna Dosymbekova
}

Dana Umirbekovna Baytukaeva

Aizat Maratkyzy Begzhan

Kazakh National University named after Al-Farabi, Karasay batyra Street, 95, 050000, Almaty, Kazakhstan

Temir Abikenovich Toktybekov

New economic University, Jandosov Street 55,050035, Almaty, Kazakhstan

Doi:10.5901/mjss.2015.v6n5s1p392

\section{Abstract}

\begin{abstract}
The authors reviewed the questions actual space activities in the Republic of Kazakhstan. Authors considered topical issues of space activities in the Republic of Kazakhstan. Experience of leading countries in the world found that space activities - a factor of high-tech and competitive development. Therefore, the implementation of projects in the field of space activities in Kazakhstan can give a strong impetus for the development of problem solving industrial-innovative sector of the economy. For the development of space activities of the Republic of Kazakhstan, the Russian space industry played an important role as Kazkosmos central state authority. The authors analyzed a number of legislative acts of the Republic of Kazakhstan concerning the industry and came to the conclusion that it is necessary to provide a strong scientific and legal support for all projects to develop space technology and technology in the exploration and use of outer space.
\end{abstract}

Keywords: space, "Baikonur" cosmodrome, Kazkosmos, space industry, the satellite.

\section{Introduction}

The head of the state of the Republic of Kazakhstan N. A. Nazarbayev in "Strategy "Kazakhstan-2050": new political policy of the consisting state" the purpose - to expand a niche of Kazakhstan in the world market of space services, and also to bring a number of projects to a realization stages is formulated. For this purpose it is necessary to plan accurately government actions in the sphere of space activity. It is important to set for itself real tasks, having defined those segments of space activity which are most interesting and demanded for Kazakhstan (President"s letter of RK, 2012).

The system of the rules of law, urged to settle space activity for research and development of celestial bodies is rather young legal sphere. By experience of the leading state of the world it is revealed that space activity is a factor of hitech and competitive development. Implementation of projects in the sphere of space activity in Kazakhstan will be able to give a strong impulse to the solution of the tasks designated in the Messages of the Head of state to the people of Kazakhstan, on development of industrial and innovative sector of national economy.

After all inclusion of results of space researches and the most diverse of prospects of astronautics in industrial production has huge economic mission. Many branches of economy already receive and have huge a number of useful information and development of scientific and technical character, using it from astronautics. This process will develop definitely thus the steps of this development will be that more, than in a bigger measure the exchange of practice of the states developers of the missile and space equipment on the basis of broad international cooperation will be adjusted.

It is possible to tell with confidents that the astronautics with its huge opportunities will serve as the right conductor of innovative development of the Republic of Kazakhstan for the benefit of its society and citizens of Kazakhstan. 


\section{Methods}

Analyzing history of development of space activity in Kazakhstan, it is conditionally possible to divide it into some stages.

First, including 1991 - 1994, I had pronounced national character: two Kazakh astronauts departed to space, implementation of the first space program of Kazakhstan began.

The second stage, from 1994 to 2004 is characterized by regulatory legal base formation.

The third, begun since 2005, it is possible to call a stage of active, practical development of space activity in Kazakhstan. This year the Decree of the Head of state formed National space agency of the Republic of Kazakhstan as the independent government body responsible for creation of space branch of the country. The state "Development of space activity in the Republic of Kazakhstan for 2005-2007" was accepted. This program along with the scientific works on research of a space included the project works connected with use of a space. In particular, the special designing and technological bureau of space equipment the aviation Ishim space rocket complex, the space Bayterek missile system, a command and measuring complex on the basis of optical and radio engineering means of the range of "Sara-Shagan" was organized.

On June 18, 2006 the Republic of Kazakhstan became the space power. This historical day from Baikonur Cosmodrome start of the first Kazakhstan KazSat satellite was carried out.

It"s done owing to close and active cooperation of two states: Russia and Kazakhstan. And already today Kazakhstan can be proud of three satellites installed in an orbit (Kulikpaeva, 2014).

The next period of space activity of Independent Kazakhstan covers 2007-2012 and is connected with activity of the National space agency (KazKosmos) formed according to the Decree of the President of the Republic of Kazakhstan from March 27, 2007. The head of state set the purpose to create modern and self-sufficient space branch in Kazakhstan, and on this way in 5 expired years powerful results are reached.

First, the space infrastructure is organized, Kazkosmos"s capable central office is created, the enterprises for all strategic directions of space activity are created. In Kazkosmos"s guide and the enterprises highly qualified personnel is picked up. The strategy of development of space activity in the Republic of Kazakhstan, the section "Space Activity" of a state program on FIIR for 2010-2014 and the industry program of development of space activity for 2010-2014 are developed. Secondly, the highly personnel kernel of scientific and engineering structure of the enterprises of space branch is created, specialists in space equipment in HIGHER EDUCATION INSTITUTIONS of the near and far abroad are trained, the special designing and technological bureau of space equipment is completed by design engineers and their training at the lead space enterprise of France is organized. In leading HIGHER EDUCATION INSTITUTIONS OF Kazakhstan training of specialists on spaces equipment and technologies is organized.

Thirdly, the communication satellite "Kazsat-2" is created, started and put into operation, there is at a completion stage a construction of a reserve land complex of management by the Kazsat series communication satellites, creation of the communication satellite „Kazsat-3”, various satellite complexes and systems within national projects and the international cooperation goes a full speed.

Fourthly, in the city of Baykonyr the fine office building in which Kazkosmos"s structural divisions and his enterprises are placed, also the house for employees of space branch that was never in the history of independent Kazakhstan is constructed.

Fifthly, there is organized and successfully well done the National center of space researches and the technologies, uniting four scientific institutes at which work well known scientists in the world. Along with further development of the traditional directions of scientific researches in the field of astrophysics, ionospheres of Earth, DZZ institutes conduct successful applied scientific researches in the new directions - creation of national system of space monitoring and system of space geodynamic monitoring, development of domestic samples of space equipment and technologies. There is organized and successfully working the Research center "Garysh-ekologiya" which is completed by qualified professionals, is equipped with modern laboratory equipment. The center are developed system of environmental monitoring of start-up of carrier rockets from Baykonur Cosmodrome and system of monitoring of health of the population living in areas of influence of activity of Baykonur Cosmodrome.

Sixly, the international cooperation in the field of research and space use in the peace purpose with the leaders who established the space power: Russia, Ukraine, France, Germany,China, India, Great Britain, Italy, Japan, South Korea, Israel, Saudi Arabia, United Arab Emirates (The official site of Kazkosmos, 2013).

Seventhly, for the first time in 20 years of independence of the Republic of Kazakhstan the bill of the Republic of Kazakhstan "About space activity" which is considered and accepted by Parliament of the Republic of Kazakhstan on January 6, 2012 is developed(«The Law of the Republic of Kazakhstan», 2012).

The structure of the Law of the Republic of Kazakhstan "About Activity"is presented by 7 heads (37 articles): 


\author{
General provisions \\ State regulation and control in the field of space activity \\ Implementation of space activity \\ Space infrastructure \\ Safety of space activity \\ Legal status and measures of social security of the candidate in astronauts, the astronaut \\ Final provisions
}

The purpose of adoption of this Law is regulation of public relations on implementation of space activity in the Republic of Kazakhstan.

Passing directly to consideration and the analysis of provisions Of the Law of RK

"About Space Activity" and also questions of implementation of international treaties, it is necessary to define first of all that there is a space activity. According to Art 1 of the Law, it is the activity directed on research and use of a space for achievement of scientific, economic, ecological, defensive, information and commercial purpose. Thus the space is defined as the space stretching outside air space at the height over hundred kilometers.

\title{
3. Results
}

The new Law of the Republic of Kazakhstan of January 6,2012 No.528-IV. About space activity", and also the relevant regulations in the field of space activity, are based on provisions of the Constitution of the Republic of Kazakhstan and fully reflect commitment of Kazakhstan to norms of international law.

Article 2 of the Law fixes a priority of the ratified international treaties before thenational legislation («The Law of the Republic of Kazakhstan», 2012, 445).

The law defines the basic principles of implementation of space activity:

observance of national interests, ensuring defense and homeland security of the Republic of Kazakhstan;

support of the priority directions of development of space activity;

economic stimulation of space activity;

compensation to harm to health of natural persons, an environmental damage, property of natural and legal

entities, the state which has arisen owing to implementation of space activity;

observance of ecological requirements, requirements in the field of technical

regulation and ensuring sanitary epidemiological wellbeing of the population;

observance of the norms of international law;

effective and national use of a space and space infrastructure of the Republic of

Kazakhstan;

stimulation of attraction of investments into development of space activity taking into account state interests of the country.

Space activity in the Republic of Kazakhstan is carried out in the following directions:

creation and use of objects of space branch;

research of a space, planets and solar and terrestrial communications;

remote sensing of Earth;

coordinate and time and navigation providing;

creation and use of space communication systems;

implementation of starts of space objects;

development of the national market of space services in the world market;

international cooperation in the field of research and space use in the in the peace purposes;

Thus, these directions of space activity cover not only national interests of the country, but also consider need of space exploration for the peace purposes with the participation of the foreign states and the international organizations for the benefit and in the interests of all states.

International cooperation in research and space use in the peace purposes is carried out according to the provisions of international law, including the UN and Contract Charter of space of 1967 (Art.1 of the Declaration of international cooperation in research and space use for the benefit and in interests of all states, with the special accounting of requirements of the developing states, the adopted resolution of 51/122 HECTARES of the UN on December 13, 1996). Kazakhstan joined the Contract on space on May 15, 1997. Stable and responsible use of a space becomes a high priority on the international scene (Abaideldinov, Kulikpayeva \& Shakhmova, 2013). 


\section{Discussion}

Today, Kazakhstan has close contacts and the relevant international contracts with such countries, as Russia, Ukraine, France, Germany, Israel, India, etc. in the field of research and space use in the peace purposes( Marchisio, 2012).

Financing of space branch in the Republic of Kazakhstan is carried out at the expense of budgetary funds. Attraction of other sources of the financing which have not been forbidden by the legislation is thus allowed.

Chapter 2 of the Law of the RK "About Space Activity" is devoted to questions of state regulation and control. In particular, competence of the Government of the RK, and also authorized body in the field of space activity is defined. That is formed in 2007. The RK presidential decree, The RK national space agency (Kazkosmos).

The law provides the state registration of space objects and the rights (Art.11) for them.

Space objects are subject to the state registration:

- Belonging to natural or legal entities of the RK, and also it is right on these space objects. In this case the state registration is understood as the accounting of space objects, the act of recognition and confirmation by the state of emergence, change or the termination of the rights for space object according to the civil legislation of the RK;

- Belonging to the foreign and legal entities, started in a space from the RK territory. In this case the state registration - is entry in the register of space objects is included in Kazkosmos"s competence. The RK "About Space Activity" provisions of the law fully reflect provisions of the Convention on registration of the objects started in a space of 1974 (Art.8) («The contract on the principles of activity of the states on research and spaceuse, including the Moon and other sky bodies», 1967,1). This information, in turn, is entered in the register ofthe Secretary-General, to which full and open access is provided (Convention on Registration of Objects Launched into Outer Space, 1974, 441). Registration of space objects gains very essential value (Koptev,1998).

Chapter 3 of the Law of the RK "About Space Activity" contains regulations on implementation of space activity and namely:

Activity licensing in the sphere of use of a space;

Basic and applied scientific researches;

Creation of space systems and space missile systems;

Use of a space communication systems;

Use of space system of remote sensing of Earth (observing the principles concerning

remote sensing of Earth from a space, the HECTARES of the UN accepted by the resolution 41/65 of December 3, 1986);

- Use of system of high-precision satellite navigation;

Use of a space missile systems («The Law of the Republic of Kazakhstan», 2012, 4).

Chapter of the Law of the RK defines objects of space infrastructure or the country.

They treat: objects of land space infrastructure an land space objects. Legal status of the Baikonur spaceport as strategic object and property complex, not privatizeable is separately fixed. Questions of utilization of space objects and technical means, making of space objects,

transfer of objects of space branch to rent to the international or foreign participant of space branch are considered. Now the Baikonur spaceport located in the territory of the RK, and is rent by the Russian Federation on the basis of the corresponding Lease ( the lease team is prolonged till 2050).

Safety of space activity has important value and include the following components (head.5) :

- Safety;

- Investigating of accidents;

- Environmental control of environmental and population state of health in the region subject to impact of space activity;

- Ban and restrictions in space activity.

In chapter 5 question of safety of space activity only at the levels of standards of the of international law are legislatively adjusted.

Thus a direct reference on the international norms, in particular standard of the

Convention on the international damage liability, 1975 caused by space objects, directly does not contain on the Law of the RK "About Space Activity" ( Sylkina, Dosymbekova, Tusupova \&Abdrakhmanova, 2014, 265).

Though Kazakhstan joined this Convention on May 15, 1997. It should be noted that in separate international agreements of the RK at bilateral level of provision on responsibility are stated (The spaceport lease "Baikonur", 
agreements on research and space use in the peace purposes, Moscow, on December 10, 1994))(«The Law of the Republic of Kazakhstan», 2012, 5).

In hl.6 the legal status and measure of a social assistance of the candidate in astronauts, the astronaut is regulated. Are considered the status of the candidate in astronauts, the astronaut; guarantees in case of mutilation, diseases of death (death), a measure of social protection. In final provisions of hl. 7 the responsibility for violation of the legislation of the RK in the field of space activity, and also an introduction order in Law action.(within 10 days after its first official publication) («The Law of the Republic of Kazakhstan», 2012, 6) is provided.

Thus, the modern period of development of space activity of the Republic of Kazakhstan is characterized by creation of domestic space branch.

Kazkosmos as the central government body successfully fitted into hierarchy of state bodies of the state and conducts active work on realization of its public policy in the field of space activity.

Achieved success is noticed by space powers. They want to develop various forms of cooperation with us on research and space use in the peace purposes. The national space agency of the Republic of Kazakhstan does all necessary to create in the country full, equitable to interests and needs of the state and society, space branch. The modern astronautics is a global satellite communication and television, high- precision space navigation, meteo - and environment monitoring, remote sensing of Earth for the purpose of studying of natural resources, cartography.

Development of space activity promotes strengthening of homeland and information security, social and economic and scientific and technical development of the Republic of Kazakhstan by effective use of space technologies.

Changes and addition in some acts of the Republic of Kazakhstan concerning space activity ( the Law of the Republic of Kazakhstan of January 6, 2012 No. 529- IV "About modification were put into operation and addition in some acts of the RK concerning space activity"), reposts Zakon.kz. (The law "About Modification and additions in Some Acts of the Republic of Kazakhstan concerning Space Activity", 2012, 5).

The main objective of the Law is reduction of acts of the Republic of Kazakhstan

"About space activity". The Law is directed on regulation of the public relations in the sphere of space activity and provides modification and additions in codes of the Republic of Kazakhstan: Criminal, Criminal procedure, About administrative offenses, Land, Budgetary,"About taxes and other obligatory payments in the budget" (Tax code), "About health of the people and a health care system"; laws "About the Housing Relations", "About Industrial Safety on Dangerous Production Objects", "About the State Control and Supervision in the Republic of Kazakhstan" (Sarsembayev, 2007, 5).

The Law enters administrative responsibility for violation of the legislation in the field of space activity, criminal liability for safety violation of the rules at implementation of space activity, and also is regulated the sphere of space activity for implementation of the state control. So, now according to the new amendments to the criminal code of the Republic of Kazakhstan, at implementation of space activity if it entailed on imprudence causing heavy or average weight of harm to health of the person, the perpetrator is punished foe safely violation of the rules by a penalty in the amount of 500 (809 000 tenges) to 1000 (1 millon 618 thousand tenges) MRP, or at a rate of a salary or other income condemned for the period from 5 to 10 months. Or corrective labors for a period of to 2 years, or restriction of freedom for a period of up to 3years, or imprisonment for the same term with deprivation of the right hold certain position or to be engaged in a certain activity for a period of up to 3 years or without that (Sarsembayev, 2007, 8).

The same act which has entailed on imprudence death of the person or other heavy

consequences, is punished by imprisonment for a period of up to six years with deprivation of the right to hold certain positions or to be engaged in a certain activity for a period of up to 3 years or without that. If the act provide by part one of the present article, entailed death of two or more person on imprudence, guilty is punished by imprisonment for a period of 3 till 8 years with deprivation of the right to hold certain positions or to be engaged in a certain activity for a period of up to 3 years or without that.

Changes concerned also the Code of the Republic of Kazakhstan about administrative offences. The code is added with article for RK violation of the law in the field of space activity. So, for the violation made in a look:

1) Implementation of the project in the field of space activity according to which there is no positive conclusion of branch examination in the field of space activity;

2) Start of space object from the territory of the Republic of Kazakhstan, and also beyond its limits in case of its implementation by the Kazakhstan participant of space activity without positive decision of the Government of the Republic of Kazakhstan on start of space object;

3) Evasion from the state registration of space object,

Attracts a penalty on natural persons in the amount of 30 (48 540 tenges) to 50 (80 900 tenges) MRP, on public officials, individual entrepreneurs - in the amount of 50 (80 900 tenges) to 100 ( 161800 tenges) 
MRP, on the legal entities are subjects of small or average business, - in the amount of 100 (161 800 tenges) to 300 (485 400 tenges) MRP, on the legal entities who are subjects of large business, - in the amount of 300 (485 400tenges) to 500 (809 000 tenges) MRP with the stay of action of the license for the right of implementation of activity in the sphere of use of a space for six months or without that (Sarsembayev, 2007, 7).

The action (inaction) provided by part one of the present article, perfect repeatedly within a year after imposing of an administratively penalty, attracts license deprivation. The safety violation of the rules at implementation of space activity if this actions has no signs of penal acts, attracts a penalty on natural persons in the amount of 10 ( 16180 tenges) to 30 (48 540 tenges) MRP, on public officials, individual entrepreneurs, the legal entities who are subjects of small or average business, - in the amount of 30 (48 540 tenges) to 50 (80 900 tenges) MRP, on the legal entities who are subjects of large business, - in the amount of 50(80 900 tenges) to 100 (161 800 tenges) MRP with of action of the license for the right of implementation of activity in the sphere of use of a space for six months or without that (Sarsembayev, 2007, 17).

Not elimination of the violations which have entailed attraction to administrative responsibility, provided part one of the present article, after the term of stay of implementation of activity in the sphere of use of a space, attracts license deprivation.

In the Land code of the RK, now there is a concept - the earth for needs of space activity. The land which have been taken away for placement and operation of objects of land space infrastructure, and also their conservation zones belong to lands for needs of space activity (The law "About Modification and additions in Some Acts of the Republic of Kazakhstan concerning Space Activity", 2012).

For population safety, and also safety and safe operation of objects of land space infrastructure conservation zones with special conditions of land use, except for areas of falling of separating parts of carrier rockets within which those kinds of activity which are not compatible to the purposes of establishment of zones are limited or forbidden are established.

The code of the Republic of Kazakhstan "About the health of the people and a health care system" was also added. Now employees of space branch can be called not only the military personnel, but also candidates in astronauts and astronauts. According to amendments to the Law of the Republic of Kazakhstan "About the housing relations", in case of death (death) of the candidate in astronauts, the right for its gratuitous receiving passes the astronaut to whom the dwelling was provided, to successors of lost (dead). Candidate in astronauts, the astronauts having length of service in the sphere of pace activity more than fifteen years, having the right to privatize the dwelling gratuitously (The law "About Modification and additions in Some Acts of the Republic of Kazakhstan concerning Space Activity", 2012, 44).

\section{Conclusion}

For realization of objectives aimed at the development of space activity are created and the Kazakhstan profile work.

At the same time general direction of development of the space industry demands search by the Republic of Kazakhstan of the place in the world space market which is caused by the increasing competition by the main participants of space activity (the Russian Federation, Japan, the USA, the People"s Republic of China, Israel, India);

Now in questions of improvement of space activity the following results were reached:

1. The project of creation of a land complex of managements of space crafts and start of a communication satellite and "Kazsat-1" broadcasting is carried out;

2. Technical recommendations and technical and economic confirmations of formation of ecologically safe space Baiterek missile system at the Baikonur spaceport, and also space system of DZZ and scientific appointment, high - precision satellite navigation are investigated;

3. Technical system of the radio range "Orbit" and the experimental Kosmostantion base in the city of Alma-Ata are improved;

4. The program of carrying out scientific development and experiments onboard the International space station is investigated;

5. A number of scientific conclusions of area, studying of the optical phenomena in the top atmosphere, radiation monitoring of a space, and in other joint development with foreign scientists is acquired:

6. Works are carried out and certain conclusions regarding development of basic infrastructure of Natural system of space monitoring of ecological safety of the territory of the Republic of Kazakhstan are acquired when using space rocket complexes (Kulikpayev, 2012,199). 
Therefore, there are serious prerequisites for further development of space branch in Kazakhstan. It is possible to refer need of improvement of high technologies, industrial development of economy, ensuring national security and defense to these prerequisites, and the most key moment is existence in property of the largest in the Baikonur spaceport world.

The area of the spaceport of 6,717 square kilometers that by the size is approximately equal to the territory of Moldova"(Centers: Baikonur: Regions and Facilities, 2015,14).

The astronautics of Kazakhstan with its huge territory and the richest resources is a sphere of geopolitical, economic and scientific and practical interests. Without this it is extremely difficult to create a common information space in our country, to study and rationally to use its natural resources, to carry out environmental monitoring. It is obviously that effective space exploration demands advancing development of basic and applied researches in such areas, as physics of near and far space, radio electronics and communication, materials science, space instrument making, remote sensing of Earth.

Proceeding from stated, in modern conditions when space activity is in the republic at a development stage, it is vital to provide powerful scientific and legal support of all projects on creation of space equipment and technologies in the field of research and space use.

\section{References}

President"s letter of RK of 2012. Social and economic modernization - the main vector of development of Kazakhstan. http://www. akorda.kz/page/poslanie-prezidentarespubliki-kazakhstan-n-a-nazarbaeva-narodu-kazakhstana_1339760819

The development program of space activity in the Republic of Kazakhstan for 2010- 2014 of http://www.zakon.kzl

The official site of Kazkosmos as of June, 2013 of http://kazkosmos.gov.kz/rul

The Law of the Republic of Kazakhstan "About space activity" of January 6, 2012 of http://www.zakon.kz/

The contract on the principles of activity of the states on research and space use, including the Moon and other sky bodies, 1967 year of http://www.un.org/ru/documents/decl_conv/conventions/outer_space_governing.shtml

The law "About Modification and additions in Some Acts of the Republic of Kazakhstan concerning Space Activity" of January 6, 2012 of http://www.zakon.kzl

Sarsembayev M.A. International space law and Republic of Kazakhstan. - Alma-Ata: ENU named by L. Gumilev, Daneker, 2003. - 182 p.

M.Zh.Kulikpayev the international space law and the law of the Republic of Kazakhstan "about space activity" of January 6, 2012 the master of international law, the doctoral candidate of $\mathrm{PhD}$ of chair of international law of law department the Euroasian national university named by L.N.Gumilev Kulikpayeva_mzh@enu.kz

Aptikeeva E.O. Improvement of management of http//sibac.info/files/2013_02_28_StudEconomy/StudEconomy28.02.2013.pdf of space branch of the Republic of Kazakhstan

Legislative portal of normative legal acts of RK, as of June, 2013 of zakon.kz.

Kulikpaeva Mira Zhumagazyevna, (2014). International legal aspects of cooperation between the Republic of Kazakhstan with other countries in the field of space activity/ http://www.enu.kzl

Yerbol Musinovich Abaideldinov, Mira Zhumagazyevna Kulikpayeva, Aigul

Anuarbekovna Shakhmova L.N. /The Republic of Kazakhstan cooperation with the Russian Federation and other countries of the world in the field of outer space/Life Science Journal 2014;11(5)

Marchisio, S., 2012. The legal dimension of the sustainability of outer space activities. X All Russian scientific-practical conference "Actual problems of modern international law" dedicated to the memory of Professor I.P. Blischenko, People"s Friendship University of Russia, pp: 156.

"Centers: Baikonur: Regions and Facilities," Russian Space Web, www.russianspaceweb.com.

Convention on Registration of Objects Launched into Outer Space, 1974. Date Views 20.03.2014, www.un.org/ru/documents/decl_ conv/conventions/outer_space

Koptev, J.N., 1998. Problems and Prospects of Russian international space activities. G. Space and Rocket, 14: 120 -121

Sylkina S.M., Dosymbekova M.S., Tusupova A.Z., Abdrakhmanova E.S. Legal analysis of the convention on International liability for damage caused by space objects. (March 29, 1972). Life Sci J 2014;11(11s):264-266] (ISSN:1097-8135). http://www.life sciencesite.com. 60, p.265 